\title{
Molecular Characterization of Aureobasidium Species in Iran
}

\author{
Mahdi Arzanlou \\ Department of Plant Protection, Faculty of Agriculture, University of Tabriz, Tabriz, Iran.
}

Received: 27 Jan 2014

Revised : 1 Mar 2014

Accepted: 17 Apr 2014

Corresponding Authors: Mycology and Plant Pathology, Plant Protection Department, Faculty of Agriculture, University of Tabriz, P O Box: 5166614766, Tabriz, Iran E-mail: arzanlou@ hotmail.com.

\begin{abstract}
Background: Members of this genus Aureobasidium are ubiquitous microorganisms which can be isolated from wide ranges of substrates such as plant materials (phyllosphere, plant debris, bark, roots, fruits and wood), soil, dead wood, air, and as rare etiologic agent of pheohyphomycosis, keratomycosis, septicemia, peritoneal sepsis, and dermatological infections in human. Very little is known on the identity, substrates and distribution of Aureobasidium spp. in Iran. Materials and Methods: 14 Aureobasidium isolates were recovered from vascular tissues of pome and stone fruit trees displaying decline symptoms in orchards of West and East Azarbaijan provinces, Iran. Pure cultures were established by using a single spore technique. The identity of the isolates were determined using sequence data from ITS-rDNA region. Phylogenetic relationship among isolates was inferred based on sequence data from ITS-rDNA.

Results: A megablast search analysis of ITS sequence data at NCBI revealed the identity of Aureobasidium isolates as A. pullulans. A phylogeny inferred using sequence data from ITS region placed our isolates together with the other $A$. pullulans var. pullulans in GenBank. Morphological and cultural characteristics were in agreement with the description for A. pullulans var. pullulans.

Conclusion: Our results represent new report on the occurrence of A. pullulans var. pullulans in Iran. As A. pullulans is known as rare etiologic agent of pheohyphomycosis, keratomycosis, septicemia, peritoneal sepsis, and dermatological infections in human, possible occurrence and involvement of $A$. pullulans in human infections should be taken into account.
\end{abstract}

Keywords: ITS-rDNA; Endophytes; Black yeast; Pullulan; Human pathogen

Please cite this article as: Arzanlou M. Molecular Characterization of Aureobasidium Species in Iran. Res Mol Med. 2014; 2 (2): $28-33$

\section{Introduction}

The genus Aureobasidium accommodates species with one-celled conidia of various shapes which are produced synchronouly from hyaline and terminal, lateral or intercalary conidiogenous cells (Hermanides-Nijhof 1977; Zalar et al. 2008; Seifert et al. 2011). Members of the genus are ubiquitous and occur on different habitats such as plant materials (phyllosphere, plant debris, bark, roots, fruits, wood), water, marine sediments, marshland, soil, air, skin, nails, stone, glass and in the clinical laboratory as a contaminant or human pathogen (Hermanides-Nijhof 1977, de Hoog \& Yurlova 1994, de Hoog et al. 1999, 2000, Urzi` et al. 1999). Aureobasidium spp. exhibit diverse life styles such as saprophytes, plant associated endophytes or pathogens and opportunistic human pathogens (Andrews et al. 2002, Loncaric et al. 2008, Martini et al. 2009). Aureobasidium pullulans, the type species of the genus, has become as one of the best-known and most studied species of this genus. This species is commonly associated with plant materials, found on the surface and in the tissues (as endophyte) of plant species. Aureobasidium pullulans is an important microorganism in industry, agriculture as well as medical. It is well known as a producer of pullulan, a biodegradable extracellular polysaccharide, with commercial significance (Singh et al. 2008, Zalar et al. 2008) and it also has been considered as a potential biocontrol agent of post harvest plant pathogens e.g., Botrytis cinerea, Penicillium expansum and Fusarium species. 
A wide range of antagonistic strategies such as competing for nutrients and space and production of numerous compounds including pectolytic enzymes, antimicrobial metabolites and high-molecular-weight polysaccharides have been detected in the interaction of A. pullulans with plant pathogenic fungi (Castoria et al. 2001, Dugan et al. 2002, Schena et al. 1999, 2003, Seibold et al. 2004, Elmer \& Reglinski 2006, Felice et al. 2008, Zalar et al. 2008, Martini et al. 2009). Aureobasidium pullulans is also known as ethological agent of phaeohyphomycosis, causing disseminated infection in humans (Revankar et al.2002).
Members of this genus are known from their asexual morphs and there in no teleomorph linked to this genus. However, based on DNA sequence data members of this genus reside in the family Dothideaceae (order Dothideales, Pzizomycotina, Ascomycota) (Schoch et al. 2006).

There is a huge paucity of knowledge on the biodiversity of Aureobasidium spp. in the mainland of Iran. The aim of this study was to explore biodiversity of Aureobasidium spp. associated with woody hosts in Northwestern zone of Iran.

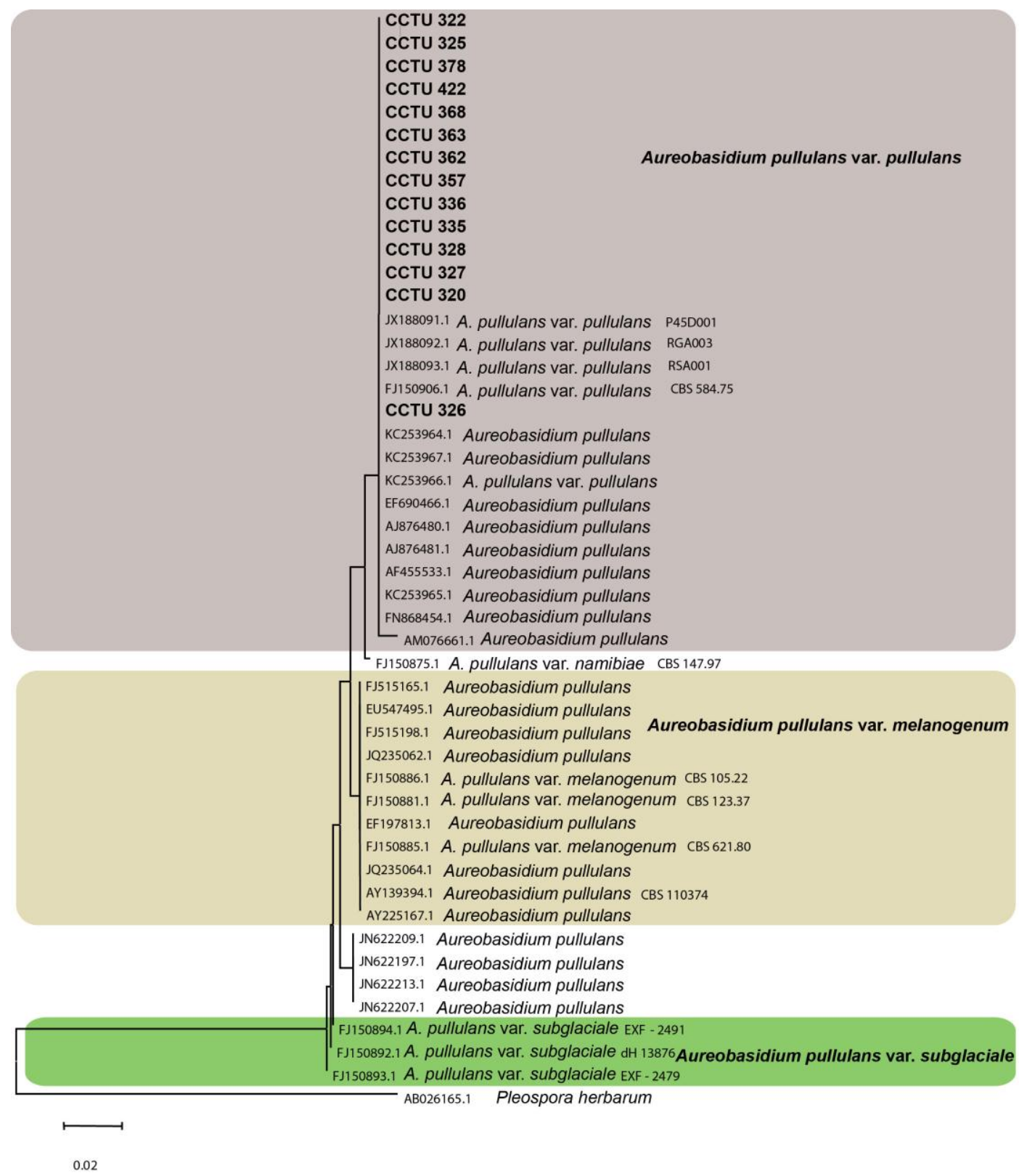

Figure 1. A neighbor-joining phylogenetic tree obtained from the ITS region and 5.8S rDNA sequence data. Bootstrap support values from 1000 replicates are indicated at the nodes. The tree was rooted to Pleospora herbarum. The scale bar indicates 0.02 substitutions per site. 


\begin{abstract}
Materials and Methods
Sampling and isolation

Wood samples were collected from branches and trunks of stone fruit trees (almond, apricot, cherry and peach) showing decline and dieback symptoms in West and East Azerbaijan provinces during growing seasons of 2009-2010. In transverse sections through wood various degrees and forms of wood discoloration and necrosis were evident. Isolation was made using the protocol explained by Arzanlou and Dokhanchi 2013a, b; Arzanlou and Torbati 2013; Arzanlou et al. 2013a, b, in brief, small pieces, approximately $5 \times 5 \times 5 \mathrm{~mm}$ were cut from just below the surface, around and in the darkened vascular tissues and submerged in 1 percent sodium hypochlorite for $30 \mathrm{sec}$, subsequently rinsed with sterile water and dried on sterile filter paper. Five pieces were transferred on to $2 \%$ malt extract agar (MEA, Fluka, Germany) amended with $2 \mathrm{ml}$ of 25 percent lactic acid per litre of medium and incubated in the dark at $25{ }^{\circ} \mathrm{C}$. Pure cultures were established by using a single-spore technique. Fungal cultures were deposited in to the culture collection of Tabriz University (CCTU) for further characterizations.
\end{abstract}

\section{DNA extraction}

Fungal isolates were grown on MEA for 15 days at $25{ }^{\circ} \mathrm{C}$ in dark. Approximately $300 \mathrm{mg}$ of fungal mycelia was scrapped from cultures and genomic DNA was extracted following the protocol of Moller et al. (1992).

\section{Sequence analysis}

The sequence data from ITS-rDNA was used for phylogenetic analysis. The primer set V9G (de Hoog and Gerrits van den Ende, 1998) and ITS4 (White et al. 1990) was used to amplify the nuclear rRNA operon spanning the $3^{\prime}$ end of the 18S rRNA gene, the first internal transcribed spacer (ITS1), the 5.8S rRNA gene, the second ITS region and the 5' end of the 28S rRNA gene from Aureobasidium isolates. The reaction mixture and PCR conditions were the same as Arzanlou et al. 2013a, b. PCR products were sequenced using BigDye Terminator v3.1 (Applied Biosystems, Foster City, CA) Cycle Sequencing Kit according to the recommendation of the seller and analyzed on an ABI Prism 3700 (Applied Biosystems, Foster City, CA). Raw sequence files were edited manually by using SeqMan ${ }^{\mathrm{TM} I I}$ (DNASTAR, Madison, Wisconsin, USA) and a consensus sequence was generated for each of the sequences. The sequences were subjected to a nucleotide Blast search at NCBI's GenBank nucleotide database and sequences with high similarity were obtained and aligned together with the sequence obtained in this study. Sequences were compared with the sequences available in NCBI's Gen Bank nucleotide (nr) database using a megablast search (Table 1). Sequence alignment was carried out by using the Clustal $\mathrm{W}$ algorithm implemented in MEGA 5 (Tamura et al., 2011). Phylogenetic analysis was performed using maximum likelihood method with program default settings in MEGA 5. Bootstrap analysis was performed with 1000 replicates. The phylogenetic tree was rooted to Pleospora herbarum (GenBank accession number AB026165.1).

\section{Results \\ Morphology}

The morphological characteristics of the isolates were in agreement with the description for Aureobasidium pullulans (Zalar et al. 2008). Colony attained a diameter about $40 \mathrm{~mm}$ after one week of incubation at $25^{\circ} \mathrm{C}$ in dark on MEA; colonies smooth and slimy with no aerial mycelium, pinkish to yellowish in surface and yellowish to light in reverse. With age, black sectors of dark pigmented hyphae or conidia developed in some isolates. On MEA, hyphae hyaline, septate, smooth, thin-walled, occasionally dark-brown hyphae developed in older cultures. Conidiogenous cells not differentiated from vegetative hyphae, terminal, intercalary or lateral on hyaline hyphae. Conidia hyaline to dark brown, generally produced synchronously on dense clusters of small denticles, sometimes formed percurrently on short lateral denticles. Conidia variable in shape and size, hyaline conidia amero, smooth, ellipsoidal, often with an inconspicuous hilum, 7-15 × 3-6.5 $\mu \mathrm{m}$. Dark brown conidia 0-1 septate, observed in some of the isolates. Yeast-like budding of hyaline and dark brown conidia frequently observed.

DNA phylogeny

The alignment file included 37 sequences (14 generated in this study and 23 obtained from GenBank) (Table 1). The phylogeny inferred using the sequence data obtained in this study together with the sequence data from GenBank, clustered our isolates with Aureobasidium pullulans from different substrates in a monophyletic group; however, several sub-clades were identified within the monophyletic clade (Figure 1). The bootstrap supports for the subclades were below 50. Three major groups corresponding to the varieties of Aureobasidium pullulans were identified in phylogenetic tree. Our isolates clustered in Aureobasidium pullulans var. pullulans clade.

\section{Discussion}

Species in the genus Aureobasidium exhibit diverse life styles such as saprophytes, plant associated endophytes or pathogens and opportunistic human 
pathogens (Andrews et al. 2002, Loncaric et al. 2008, Martini et al. 2009). A. pullulans, the type species of the genus, is the most well know species in this genus with industrial, agricultural as well as medical importance. It is well known for its commercial product, pullulan, a biodegradable extracellular polysaccharide (Singh et al. 2008, Zalar et al. 2008) and a potential biocontrol agent of post harvest plant pathogens.

Table 1. List of Aureobasidium isolates subjected to DNA sequence analyses.

\begin{tabular}{|c|c|c|}
\hline Collection Code & Host/ substrate & Origin \\
\hline CCTU 320 & Peach & Iran \\
\hline CCTU 322 & Peach & Iran \\
\hline CCTU 325 & Peach & Iran \\
\hline CCTU 326 & Apricot & Iran \\
\hline CCTU 327 & Cherry & Iran \\
\hline CCTU 328 & Almond & Iran \\
\hline CCTU 335 & Peach & Iran \\
\hline CCTU 336 & Apricot & Iran \\
\hline CCTU 357 & Apricot & Iran \\
\hline CCTU 362 & Peach & Iran \\
\hline CCTU 363 & Apricot & Iran \\
\hline CCTU 368 & Apricot & Iran \\
\hline CCTU 378 & Apricot & Iran \\
\hline CCTU 422 & Soil & Iran \\
\hline UOA11686: KC253964.1 & Cerebrospinal fluid & Greece \\
\hline UOA12768B: KC253967.1 & Otitis & Greece \\
\hline UOA12688A: KC253966.1 & Skin & Greece \\
\hline C202: AM076661.1 & Plantago lanceolata, roots & Germany \\
\hline TJY13b: EF690466.1 & Marine & China \\
\hline MT 7: AJ876480.1 & Steganacarus magnus (oribatid mite) & Germany \\
\hline MT 5: AJ876481.1 & Steganacarus magnus (oribatid mite) & Germany \\
\hline wb149: AF455533.1 & Nasal mucus & Austria \\
\hline UOA12626: KC253965.1 & Pre-cooked pasta meal & Greece \\
\hline BLE6: FN868454.1 & Pinus halepensis & Spain \\
\hline Z-28: JN622213.1 & Populus euphratica & China \\
\hline Z-20: JN622207.1 & Populus euphratica & China \\
\hline Z-3: JN622197.1 & Populus euphratica & China \\
\hline Z-23: JN622209.1 & Populus euphratica & China \\
\hline LB3: AY225167. & Saraca indica & Thailand \\
\hline
\end{tabular}




\begin{tabular}{|c|c|c|}
\hline Collection Code & Host/ substrate & Origin \\
\hline CO-4: EU547495.1 & Fermented tea & Korea \\
\hline UM16: FJ515198.1 & Sea surface & Taiwan \\
\hline P-19: JQ235062.1 & Populus euphratica & China \\
\hline HK58-3(1): EF197813.1 & Marine & China \\
\hline P-21: JQ235064.1 & Populus euphratica & China \\
\hline CBS 110374: AY139394.1 & Air sample & Thailand \\
\hline P45D001: JX188091.1 & Vitis vinifera & USA \\
\hline RGA003: JX188092.1 & Vitis vinifera & USA \\
\hline RSA001: JX188093.1 & Vitis vinifera & USA \\
\hline CBS 584.75: FJ150906.1 & Vitis vinifera & France \\
\hline CBS 147.97: FJ150875.1 & Dolomitic marble & Namibia \\
\hline CBS 105.22: FJ150886.1 & - & - \\
\hline CBS 123.37: FJ150881.1 & - & - \\
\hline CBS 621.80: FJ150885 & Deteriorated army supplies & Russia \\
\hline P-21: JQ235064.1 & Populus euphratica & China \\
\hline EXF-2491: FJ150894.1 & Subglacial ice & Norway \\
\hline dH 13876: FJ150892.1 & Coastal ponds of melted & Norway \\
\hline EXF-2479: FJ150893.1 & Glacial ice from sea water & Norway \\
\hline
\end{tabular}

Based on cultural and morphological differences among the isolates several varieties have been distinguished: var. pullulans, occurring particularly in (occur on the phyllosphere and slightly osmotic substrates); var. melanogenum, (occur in watery habitats); var. subglaciale (known from subglacial ice); var. namibiae (a single strain known from dolomitic marble) and var. aubasidani (Zalar et al. 2008). These varieties have been described based on the variation in physiological, cultural and micromorphological features.

A wide range of molecular markers (rDNA RFLP and UP-PCR/hybridisation) have been used to explore intraspecies variations in A. pullulans (Yurlova et al. 1996). In their study Yurlova et al. (1996) identified four groups among the Aureobasidium strains; however, there was no correlation with morphological differences. Zalar et al. 2008 applied sequence data from rDNA (internal transcribed spacers, partial $28 \mathrm{~S}$ rDNA), and partial introns and exons of genes encoding $\beta$-tubulin (TUB), translation elongation factor $(\mathrm{EF} 1 \alpha)$ and elongase (ELO) to characterise the genetic variability among A. pullulans from diverse substrates. We used sequence data from ITS region to characterize the isolates obtained from stone fruit trees. Our isolates clustered in var. pullulans clade (Figure 1).

This study represents new report on the occurrence of A. pullulans var. pullulans in Iran. To the best of our knowledge, stone fruit trees (peach, cherry, almond and apricot) are reported as new hosts for $A$. pullulans var. pullulans. The antagonistic potential of these isolates against plant pathogenic species as well as pullulan production remain to be tested.

\section{Acknowledgements}

The authors would like to thank the Research Deputy of the University of Tabriz and the Studienstiftung Mykologische Systematik und Ökologie, for financial support.

\section{References}

1. Andrews JH, Spear RN, Nordheim EV. Population biology of Aureobasidium pullulans on apple leaf surface. Can J Microbiol 2002; 48(6): 500-13. PMID: 12166677

2. Arzanlou M, Dokhanchi H. Calosphaeria canker of almond 
caused by Calosphaeria pulchella in Iran. Arch Phytopathol Plant Protect. 2013a; 46 (2): 215-26.

3. Arzanlou M, Dokhanchi H. Phenotypic and molecular characterization of Diplodia seriata, the causal agent of canker and twig dieback disease on mulberry in Iran. Arch Phytopathol Plant Protect. 2013b; 46 (6): 682-94.

4. Arzanlou M, Torbati M. Characterization and pathogenicity of Colletotrichum acutatum, the causal agent of anthracnose on Cornus mas in Iran. Arch Phytopathol Plant Protect. 2013; 46 (5): 518-825.

5. Arzanlou M, Narmani A, Moshari S, Khodaei S. Pome and stone fruit trees as possible reservoir hosts for Phaeoacremonium spp., the causal agents of grapevine esca disease, in Iran. Arch Phytopathol Plant Protect. 2013a; 47: 717-27.

6. Arzanlou M, Narmani A, Moshari S, Khodaei S, Bababi-ahari A. . Truncatella angustata associated with grapevine trunk disease in Northern Iran. Arch Phytopathol Plant Protect. 2013b; 46 (10): $1168-81$

7. Castoria R, de Curtis F, Lima G, Caputo L, Pacifico S, de Cicco V. Aureobasidium pullulans (LS-30) an antagonist of postharvest pathogens of fruits: study on its modes of action. Postharvest Biol Technol. 2001; 22: 7-17.

8. de Hoog GS, Guarro J, Gené J, Figueras MJ. Atlas of Clinical Fungi, 2nd ed. Centraalbureau voor Schimmelcultures, Universitat Rovira i Virgili, Utrecht, Reus. 2000; 1126 pp.

9. de Hoog GS, Yurlova NA. Conidiogenesis, nutritional physiology and taxonomy of Aureobasidium and Hormonema. Antonie van Leeuwenhoek. 1994; 65(1): 41-54. PMID: 8060123

10. Hoog GS de, Gerrits van den Ende AHG. Molecular diagnostics of clinical strains of filamentous Basidiomycetes. Mycoses. 1998; 41(5-6): 83-189. PMID: 9715630

11. de Hoog GS, Zalar P, Urzì C, de Leo F, Yurlova NA, Sterflinger K. Relationships of dothideaceous black yeasts and meristematic fungi based on $5.8 \mathrm{~S}$ and ITS2 rDNA sequence comparison. Stud Mycol. 1999; 43: 31-37.

12. Dugan FM, Lupien SL, Grove GG. Incidence, aggressiveness and in planta interactions of Botrytis cinerea and other filamentous fungi quiescent in grape berries and dormant buds in Central Washington State. J Phytopathol. 2002; 150: 375-81.

13. Elmer PAG, Reglinski T. Biosuppression of Botrytis cinerea in grapes. Plant Pathol. 2006; 55: 155-77.

14. Felice DV de, Solfrizzo M, De Curtis F, Lima G, Visconti A, Castoria R. Strains of Aureobasidium pullulans can lower ochratoxin A contamination in wine grapes. Phytopathology. 2008; $98,1261-70$.

15. Hermanides-Nijhof EJ. Aureobasidium and allied genera. Stud Mycol. 1977; 15: 141-222.

16. Loncaric I, Donat C, Antlinger B, Oberlerchner JT, Heissenberger B, Moosbeckhofer R. Strain-specific detection of two Aureobasidium pullulans strains, fungal biocontrol agents of fire blight by new, developed multiplex-PCR. J Appl Microbiol. 2008; 104(5): 1433-41. PMID: 18070035

17. Martini M, Musetti R, Grisan S, Polizzotto R, Borselli S, Pavan $\mathrm{F}$, Osler R. DNA-dependent detection of the grapevine fungal endophytes Aureobasidium pullulans and Epicoccum nigrum. Plant Dis. 2009; 93: 993-98.

18. Moller EM, Bahnweg G, Geiger HH. A simple and efficient protocol for isolation of high molecular weight DNA from filamentous fungi, fruit bodies, and infected plant tissues. Nucleic Acids Res. 1992; 20(22): 6115-16. PMID: 1461751

19. Revankar SG, Sutton DA, Rinaldi MG. Primary central nervous system phaeohyphomycosis: a review of 101 cases. Clin Infect Dis. 2004: 38(2): 206-16. PMID: 14699452

20. Schena L, Ippolito A, Zahavi T, Cohen L, Nigro F, Droby S. Genetic diversity and biocontrol activity of Aureobasidium pullulans isolates against postharvest rots. Postharvest Biol Technol. 1999; 17: 189-99.

21. Schena L, Nigro F, Pentimone I, Ligorio A, Ippolito A. Control of postharvest rots of sweet cherries and table grapes with endophytic isolates of Aureobasidium pullulans. Postharvest Biol Technol. 2003; 30: 209-20.

22. Schoch CL, Shoemaker RA, Seifert KA, Hambleton S, Spatafora JW, Crous PW. A multigene phylogeny of the Dothideomycetes using four nuclear loci. Mycologia. 2006; 98(6): 1041-52. PMID: 17486979

23. Seibold A, Fried A, Kunz S, Moltmann E, Lange E, Jelkmann W. Yeasts as antagonists against fire blight. EPPO Bulletin. 2004; 34: 389-90.

24. Seifert K, Morgan-Jones G, Gams W, Kendrick B. The genera of Hyphomycetes. Utrecht: CBS-KNAW Fungal Biodiversity Centre; 2011; p.997.

25. Singh RS, Saini GK, Kennedy JF. Pullulan: microbial sources, production and applications. Carbohydr Polym. 2008; 73(4): 51531. PMID: 26048217

26. Tamura K, Nei M, Kumar S. MEGA5: molecular evolutionary genetics analysis using maximum likelihood, evolutionary distance, and maximum parsimony methods. Mol Biol Evol. 2011; 28(10): 2731-39. PMID: 21546353

27. Urzì C, De Leo F, Lo Passo C, Criseo G. Intra-specific diversity of Aureobasidium pullulans strains isolated from rocks and other habitats assessed by physiological methods and by random amplified polymorphic DNA (RAPD). J Microbiol Methods. 1999; 36(1-2): 95-105. PMID: 10353803

28. White TJ, Bruns TD, Lee SB, Taylor JW. Amplification and sequencing of fungal ribosomal RNA genes for phylogenetics. In: Innis N, Gelfand D, Sninsky J, White TC, edithors. PCR-Protocols and Applications-A Laboratory Manual. New York: Academic Press; 1990. P.315-22

29. Yurlova NA, de Hoog GS, Gerrits van den Ende AHG.Taxonomy of Aureobasidium and allied genera. Stud Mycol. 1999; 43: 63-69.

30. Yurlova NA, Uijthof JM, de Hoog GS. Distinction of species in Aureobasidium and related genera by PCR-ribotyping. Antonie van Leeuwenhoek. 1996; 69(4): 323-29. PMID: 8836430

31. Zalar P, Gostinčar C, Hoog, GS de, Uršič V, Sudhadham M, Gunde-Cimerman N. Redefinition of Aureobasidium pullulans and its varieties. Stud Mycol. 2008; 61: 21-38. PMID: 19287524 